\title{
Direct ascending aortic versus peripheral arterial cannulation for type A acute aortic dissection
}

\author{
K Kamiya ${ }^{1 *}$, K Doi $^{2}$, K Meshii $^{2}$, Y Okada ${ }^{2}$, Y Soga ${ }^{2}$ \\ From 23rd World Congress of the World Society of Cardio-Thoracic Surgeons \\ Split, Croatia. 12-15 September 2013
}

\section{Background}

The optimal site of arterial cannulation in acute type A aortic dissection (AAD) surgery remains controversial. We retrospectively investigated our experience with ascending aortic (central) cannulation as an alternative to femoral or axillary (peripheral) procedures.

\section{Methods}

We enrolled consecutive 45 patients who underwent type A AAD repair from January 2007 to March 2012. Central cannulation was applied under ultrasound guidance using the Seldinger technique in 33 patients and in 12 patients through peripheral cannulation. After the distal aortic anastomosis, antegrade systemic reperfusion was established with prosthetic side arm. Two groups were compared on the basis of comorbidities, mortality, and complications.

\section{Results}

Preoperative patient characteristics were almost comparable between two groups. Central cannulation was safely performed in all 33 cases. Preoperatively, thirteen patients (28.9\%) had shock state with cardiac tamponade, the overall hospital mortality was $15.6 \%$. Intraoperative data including operation time, cardiopulmonary bypass $(\mathrm{CPB})$ time, and selective cerebral perfusion showed significantly shorter in the central group $(\mathrm{P}<0.05)$. In particular, the central group had significantly shorter time in central cooling and re-warming during $\mathrm{CPB}$ than the peripheral group $(\mathrm{P}<0.0001)$. In postoperative morbidities, the central group had shorter mean ventilation time $(\mathrm{P}=0.03)$ and the duration of ICU stay $(P=0.002)$. Additionally, the central group experienced significantly fewer acute lung injury (ALI) than the peripheral group $(\mathrm{P}=0.04)$.

\footnotetext{
* Correspondence: kamiya@mie-heartcenter.com

${ }^{1}$ Division of Cardiovascular Surgery, Mie Heart Center, Mie, Japan
}

Full list of author information is available at the end of the article

\section{Conclusions}

Direct central cannulation produced acceptable early surgical outcomes. This procedure especially enabled to establish the rapid cooling and re-warming on CPB, which might contribute to the lower incidence of postoperative ALI than the conventional peripheral access. Our results suggested ascending aorta is a safe alternative cannulation site for the repair of type A AAD.

\section{Authors' details}

${ }^{1}$ Division of Cardiovascular Surgery, Mie Heart Center, Mie, Japan.

2Division of Cardiovascular Surgery, Nagahama City Hospital, Shiga, Japan.

Published: 11 September 2013

doi:10.1186/1749-8090-8-S1-O22

Cite this article as: Kamiya et al.: Direct ascending aortic versus

peripheral arterial cannulation for type A acute aortic dissection. Journal of Cardiothoracic Surgery 2013 8(Suppl 1):O22.

Submit your next manuscript to BioMed Central and take full advantage of:

- Convenient online submission

- Thorough peer review

- No space constraints or color figure charges

- Immediate publication on acceptance

- Inclusion in PubMed, CAS, Scopus and Google Scholar

- Research which is freely available for redistribution 